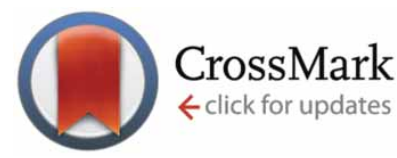

\title{
Smoking bans, politics and respiratory medicine
}

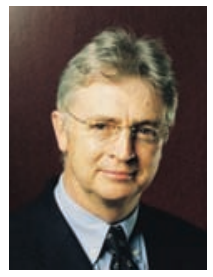

W. MacNee

ERS President

ELEGI / Colt Research Labs University of Edinburgh

MRC Centre for Inflammation Research

The Queen's Medical Research Institute

Edinburgh

Scotland

UK

Fax: 441312426582

E-mail:w.macnee@ed.ac.uk
Exposure to environmental tobacco smoke (ETS) - so-called "passive smoking" - remains a major source of excess morbidity and mortality in Europe and places a significant burden on society. A comprehensive and coordinated effort towards a "smoke-free Europe" should be one of the major priorities in public health and is considered as such by the European Commission (EC), which committed itself in its Environmental and Health Action Plan (2004-2005) to "develop work on improving indoor air quality in particular by encouraging the restriction of smoking in all workplaces by exploring both legal mechanisms and health promotion initiatives at both European and member state level". There have been significant steps in the EU to promote smoke-free environments, and in this issue of Breathe, the experience of the legislation against smoking in public places in Ireland provides information on how this can be achieved and the impacts of such a ban. A further article in this issue on tobacco control in central and eastern Europe indicates the need for further efforts in this area.

The justification for smoking bans in public places has been linked to health and safety at work directives by the EU. National legislation in this area differs widely across the member states, but the excellent examples set by Ireland, Italy, Malta, Sweden and parts of the UK should encourage other member states to make progress to introduce effective measures to protect citizens from the harmful effects of passive smoking.

On an international level, the World Health Organization Framework Convention on Tobacco Control (WHOFCTC), which has been signed by 168 groups including the European Community and organisations such as the European Respiratory Society (ERS), has "recognised that scientific evidence has unequivocally established that exposure to tobacco smoke causes death, disease and disability". The facts related to morbidity and mortality in passive cigarette smoking have been emphasised in the report "Lifting the Smokescreen" [1], commissioned by a partnership between the ERS Cancer Research UK and the Institut National du Cancer in France, which indicated that more than 79,000 adults die each year as a result of passive cigarette smoking in the (at the time) 25 countries of the EU. Exposure at work accounted for 7,000 of these deaths in the $\mathrm{EU}$, while exposure at home was responsible for a further 72,000 deaths.

Creating smokefree environments not only protects people from harm caused by ETS exposure, but also contributes to a reduction in tobacco consumption in the whole population, thus reducing illness and mortality from major diseases, particularly respiratory and cardiovascular. These improvements can be expected within 1-5 years. The CHOICE project from the WHO [2] identified smoke-free public free places as the second-most effective form of intervention, after tax increase, to reduce mortality and morbidity related to tobacco use. A further important indirect effect of "smokefree" policies is an increase in the awareness of the danger of active and passive smoking in the population and its contribution to the "de-normalisation" of smoking within society. This would be expected to lead to a change in smoking behaviour and to help to make it easier for smokers to decide to give up smoking [3], to discourage young children and young people from taking up smoking [4], and to deter smokers from smoking in the presence of nonsmokers, in particular children and pregnant women [5]. As a party to the WHOFCTC the European Community is under a legal obligation to develop smoke-free environments. Comprehensive bans on smoking in all enclosed public places and all workplaces, including bars and restaurants, has already been introduced in Ireland (March 2004), Scotland (March 2006) and in Northern Ireland, and in England and 


\section{EDITORIAL}

Wales complete smoke-free legislation is due to come into force by the summer of 2007.

Smokefree legislation, with some exemptions, has been introduced in Italy (January 2005), Malta (April 2005) and Sweden (June 2005). This permits employers to create special sealed smoking rooms with separate ventilation systems. Similar measures have just been introduced in France with a transition period for hospitality venues until January 2008, in Lithuania (with some exceptions), and they will come into force in Finland in June 2007. There is a clear trend towards smoke-free environments throughout the EU member states, driven among other factors by legal requirements at EU and international level. As a result of incomplete regulations or lack of enforcement, national government or employers have faced litigation by citizens for damage to their health caused by passive smoking [6].

The EC has just issued a Green Paper on smoke-free workplaces. Important stakeholders, including the ERS, have been asked to comment. This Green Paper outlines the spectrum of smoke-free initiatives. These range from a comprehensive approach, consisting of a total ban on smoking in all enclosed or substantially enclosed workplaces and public places including means of public transport, to measures involving smoke-free regulation with exemptions, particularly for the hospitality sector. The most effective policy in this area in terms of improving health would be a comprehensive smoke-free regulation, which in addition would have the biggest potential to denormalise smoking in society and do most to create an environment that encourages smokers to cut back or give up smoking and discourages young people from taking up smoking.

A review of workplace studies has suggested that totally smoke-free workplaces are associated with a reduction in smoking prevalence of 3.8\% [7]. Comprehensive smoking bans are associated with reductions in active smoking, as shown in smoke-free countries where a fall in tobacco sales (by $8 \%$ in Italy and $14 \%$ in Norway) was associated with a significant increase in attempts

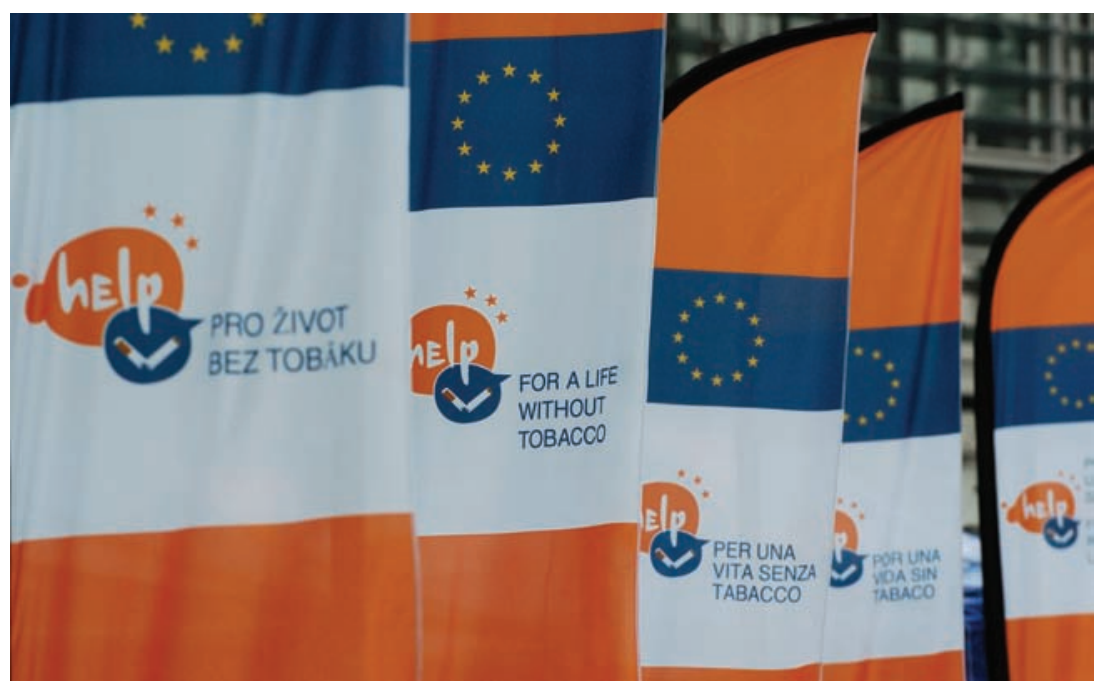

to quit smoking $[8,9]$. In Ireland, $80 \%$ of ex(c) European Community 2007.

smokers cited the new legislation as the motivation to give up smoking while $88 \%$ declared that the law had helped them not to start again [10].

Smoke-free regulations, with exemptions, still leave some of the most vulnerable groups exposed to environmental tobacco smoke and reduce the impact on denormalising smoking behaviour.

The EC in its Green Paper outlines the different policy options available to achieve smoke free objectives. Continuing with the status quo would be a lost opportunity to build on the current political momentum towards smoke-free areas in the EU. Voluntary measures within member states or EU commission or council recommendations without any binding legislation would be less effective. Binding legislation that imposes an enforceable basic level of protection from ETS throughout the member states is clearly the best option.

Taking into account the unequivocal scientific evidence of the harm caused by second-hand smoke and the impact of clean indoor air policies on the overall reduction in tobacco use, we should as the respiratory community advocate that the EC introduces the policy with the widest scope to bring the biggest public health benefit to the population. 
References

1. The Smoke Free Partnership. Lifting the Smokescreen: 10 Reasons for a Smoke Free Europe. Brussels, ERSJ Ltd, 2006. Available at: www.european-lung-foundation.org/uploads/Document/WEB_CHEMIN_282_1142435970.pdf. Date last accessed: February 6, 2007.

2. WHO-CHOICE webpage. EUR A: Cost effectiveness results for Tobacco Use. www.who.int/choice/results/tob_eura/en/index.html. Date last accessed: February 6, 2007.

3. Chapman S, Borland R, Scollo M, Brownson RC, Dominello A, Woodward S. The impact of smoke-free workplaces on declining cigarette consumption in Australia and the United States. Am J Public Health 1999; 89: 1018-1023.

4. Wakefield MA, Chaloupka FJ, Kaufman NJ, Orleans CT, Barker DC, Ruel EE. Effect of restrictions on smoking at home, at school, and in public places on teenage smoking: cross sectional study. BMJ 2000; 321: 333-337.

5. Borland R, Yong HH, Cummings KM, Hyland A, Anderson S, Fong GT. Determinants and consequences of smoke-free homes: findings from the International Tobacco Control (ITC) Four Country Survey. Tob Control 2006; 15: Suppl. 3, iii42-iii50.

6. European Network for Smoking Prevention (ENSP). Smoke Free Workplaces: Improving the Health and Well-being of People at Work. Brussels, ENSP, 2001; pp. 84-97.

7. Fichtenberg CM, Glantz SA. Effect of smoke-free workplaces on smoking behaviour: systematic review. BMJ 2002; 325: 188191.

8. Gallus S, Zuccaro P, Colombo P, et al. Effects of new smoking regulations in Italy. Ann Oncol 2006; 17: 346-347.

9. Lund M, Lund KE, Rise J, Aarø LE, Hetland J. Smoke-free bars and restaurants in Norway. Oslo/Bergen, SIRUS/HEMIL, 2005. Available at: http://www.globalink.org/documents/2005smokefreebarsandrestaurantsinNorway.pdf. Date last accessed: February 6, 2007.

10. Fong GT, Hyland A, Borland R, et al. Reductions in tobacco smoke pollution and increases in support for smoke-free public places following implementation of comprehensive smoke-free workplace legislation in the Republic of Ireland: findings from the ITC Ireland/UK survey. Tob Control 2006; 15: Suppl. 3, iii51-iii58.

\section{Ask the Expert - pulmonary rehabilitation}

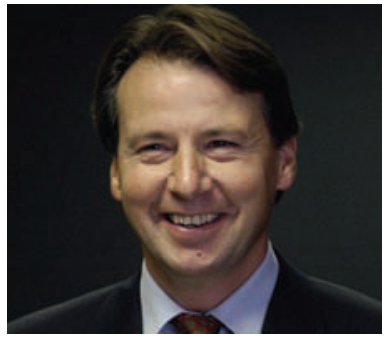

Many thanks to those of you who sent an email to Stephen Spiro and Mark Elliot after the request in the last edition of Breathe for your questions on the subjects of lung cancer and NIV, respectively. We received a good range of questions, the answers to some of which can be found on pages 249 and 264. We apologise to any of you whose questions weren't directly answered. However, those felt to be most useful to a wider audience were answered and published in the limited space available.

The good news is that we have another expert for the June issue of Breathe: Prof. Rik Gosselink from the Respiratory Rehabilitation and Respiratory Division of the University Hospital Gasthuisberg (Leuven, Belgium).

We hope that many of you will use this opportunity to ask questions on the following subjects:

- exercise testing \& training

- physiotherapy

- pulmonary rehabilitation

- physiotherapy in the ICU

- research methods in physiotherapy

Please send any questions you have to breathe@ersj.org.uk by April 20, 2007. 